\title{
PRODUCTION OF DIGITAL ELEVATION MODELS USING TOTAL STATION DEVICE
}

\author{
RASHEED SALEEM ABED
}

PhD., Remote Sensing Center, University of Mosul. Mosul, Iraq

ABSTRACT
Digital Evaluation Model (DEM) is used to represent the shape of the earth and is considered one of the most
important data that most planning, engineering and agricultural projects start with. Previously, getting them cost a lot
of effort and time. At present, modern methods of obtaining this data appeared to be used. This research reviews the
use of the Total Station in rural elevated area to obtain this data and infer contour lines from it. The work shows
agreat shortening of time and appropriate accuracy that was obtained in collecting and analyzing this data.
KEYWORDS: DEM, Total Station, Mapping \& Contouring

Received: Jun 15, 2020; Accepted: Jul 06, 2020; Published: Jul 25, 2020; Paper Id.: IJCSEIERDAUG20204

\section{INTRODUCTION}

The Digital Elevations Model (DEM) of the earth's surface is among the most important data needed inmany disciplines such as engineering, planning, agriculture, etc. It provides the possibility of selecting the best sites for the establishment of a particular project, estimating the cost of construction and selecting alternatives.

There are many ways of obtaining such data, from the traditional leveling device to GPS devices and imaging devices, as well as laser scans and total stations. (Wolf, 2002. Kavannagh,2010. Charles D, 2008, 2006).

Each of these technologies has its advantages and difficulties in terms of cost, accuracy and speed of completion.

In engineering, workrequires accuracy and speed.The total station has been used for this work.

In this research, the work carried out at a proposed site for an engineering project is explained in order to start construction and rehabilitation.

There are two main formats for storing digital elevation data : DEM and TIN. Mostly, DEM refers to a regular grid of data storage, while the TIN refers to random collection of points and storage. Of course, the conversion between these two formats is possible with specialized software.

The Total Station unit consists of the following parts

- Electronic distance measurement device (uses electromagnetic radiation to measure distances)

- Electronic theodolite.

- Internal digital Processor.

- Memory for data storage 
- Work often needs the availability of a reflector.

The device reads the oblique distances towards the target, as well as horizontal and vertical angles from which the coordinates of the target are calculated. There ismuch more information that can be obtained depending on the choice of the user of the device. The device is able to collect and store data for each point monitored and depending on the speed of work, that can reach 1000 points per day.

In general, the distance accuracy of these devices is in the order of $\pm(2 \mathrm{~mm}+2 \mathrm{ppm} \times$ Distance) $\mathrm{m}$.s.e (Topcon Corporation,2009). However, the accuracy of measuring vertical levelsis lower.

Most of the measurements performed on natural ground do not require high metric accuracy, so the total station is suitable for the works of the contouring for land and volume calculations, etc. In this work, we utilized the Total Station TOPCON 235N [4] which is a wideranging, low-cost device with a measurement range of 3,000 meters using a single reflector.Popular software such as AutoCAD, Surfer and Excel have also been used to handle the data.

\section{FIELD WORK}

The study area of this project is a hill of about 27 meters high from the surrounding area, which is part of residential land. The work aims to repair the damage to one of the high water tanks placed at the highest location.Figure 1.

Due to the nature of the work area, a number of ground control points have been distributed in different locations on which the device is located and a local ground coordinate system has been adopted, which is sufficient for limited work that does not need to deal with global coordinates. The most important factor in determining the choice of control and instrument points is the intervisibility between at least two of them also the possibility of installing the device to take the required measurements. When the device is setover any point, consideration is taken to account that the correct aiming is carried out at a known point in order to continue the correct connection during the subsequent transfers of the device.

Although the main objective is to collect natural earth levels, the work may need to introduce additionalpoints within the workspace and this can be done by adding attributes or abbreviated definitions for some points. These are necessary to complete the plan of the area. These definitions help to identify that the point in question is useful or that it has other significance (land, street or other location boundaries). 


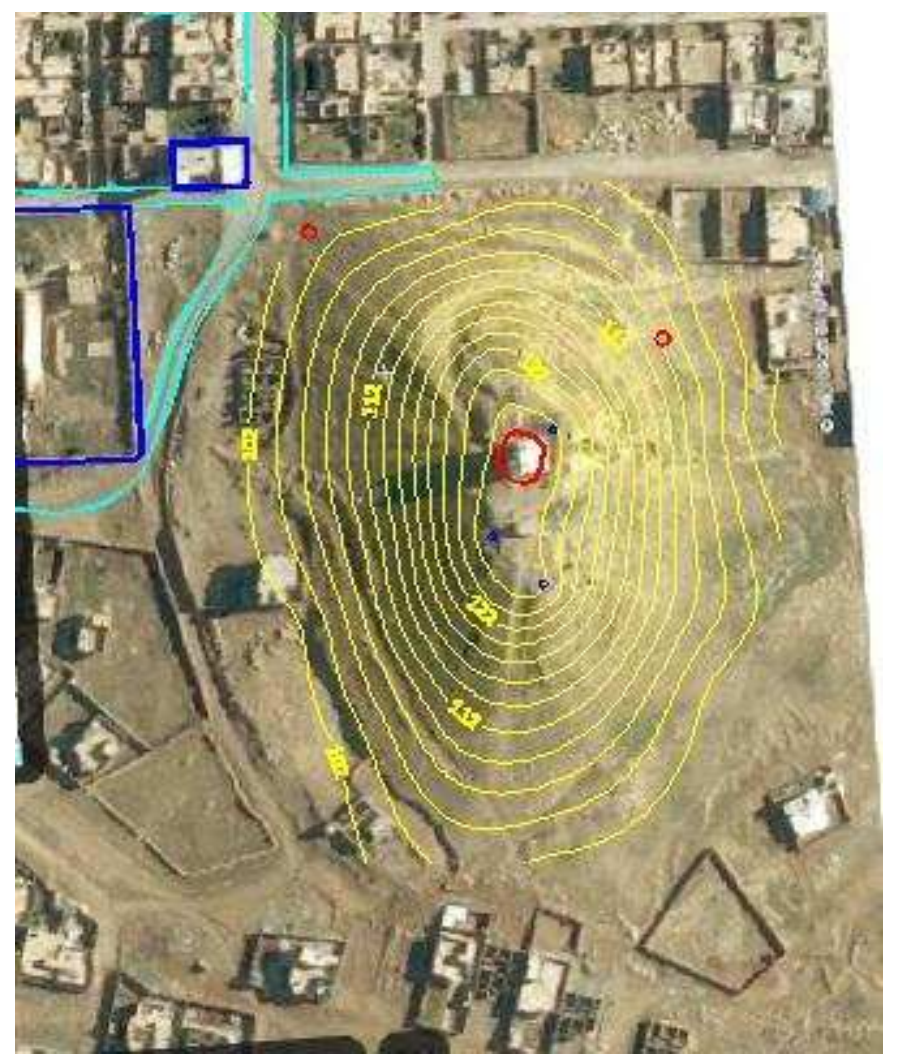

Figure 1: Study area and the hill part

\section{OFFICE WORK AND RESULTS}

A program that converts a batch of coordinate data obtained from the total station device into a format of (script file) that is understood by AutoCAD has been written. Since the points are consecutive in the run, the drawing will be in the form of successive points connected by polylines. This method facilitates the search for points and discovers any possible errors in them and shows. Figure 2 shows a polyline of sequence of these points as collected in the work field.

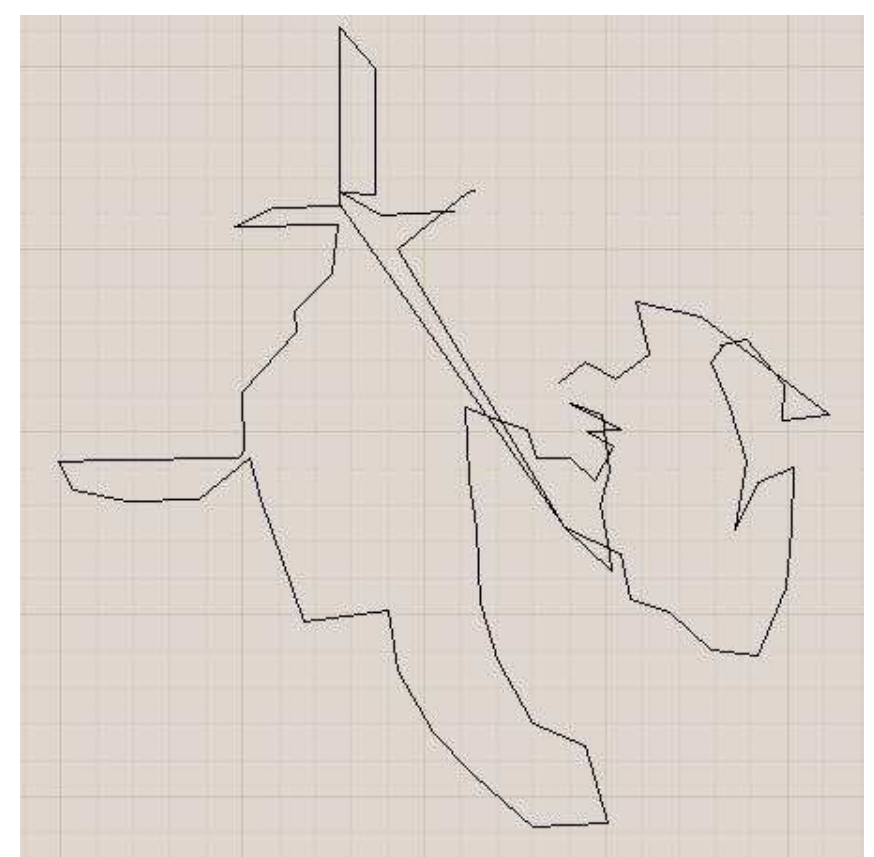

Figure 2: Field course of points sequencing in data collection 
The appropriate points were used and properly converted using Excel and Surfer programs to extract the contour lines from them. The drawing of the contour lines was completed, as well as two side sections of the hill site.

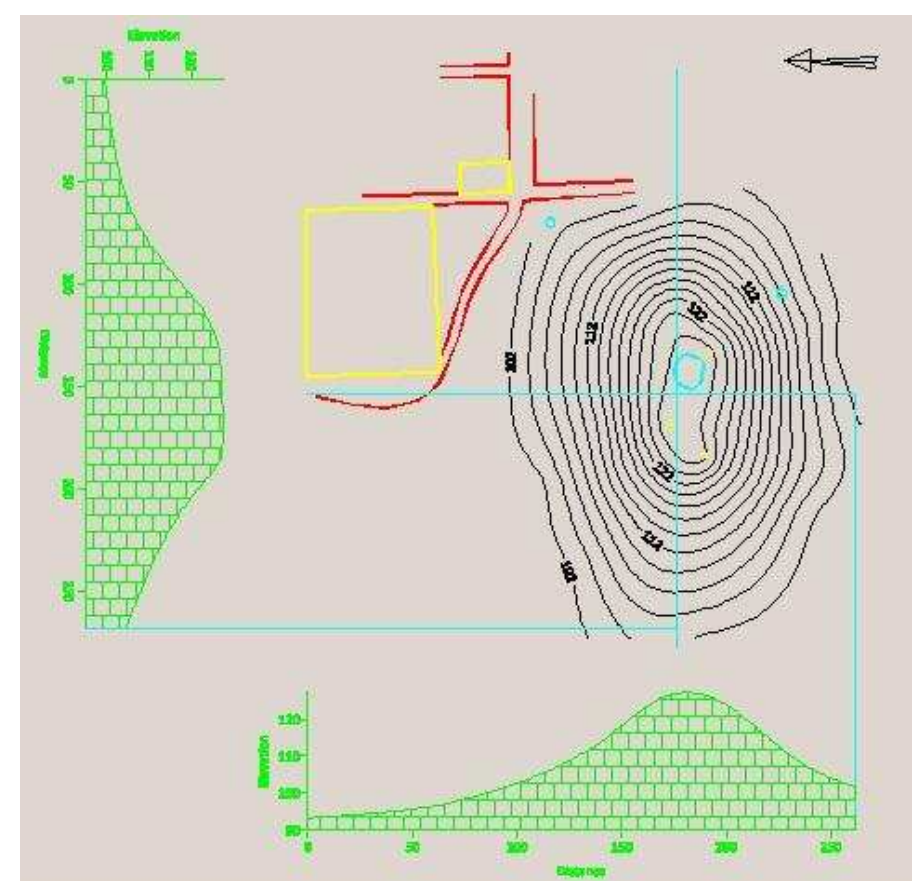

Figure 3: Contour map of the work area with two sections

Based on the information available in the digital data obtained, the earth's inclination angles were obtained andsuperimposed on the contour map. Figure 4 shows the regular grid of inclination angle data. Of most interest, among thedata that we have, isthe highest angle value of 25 degrees.

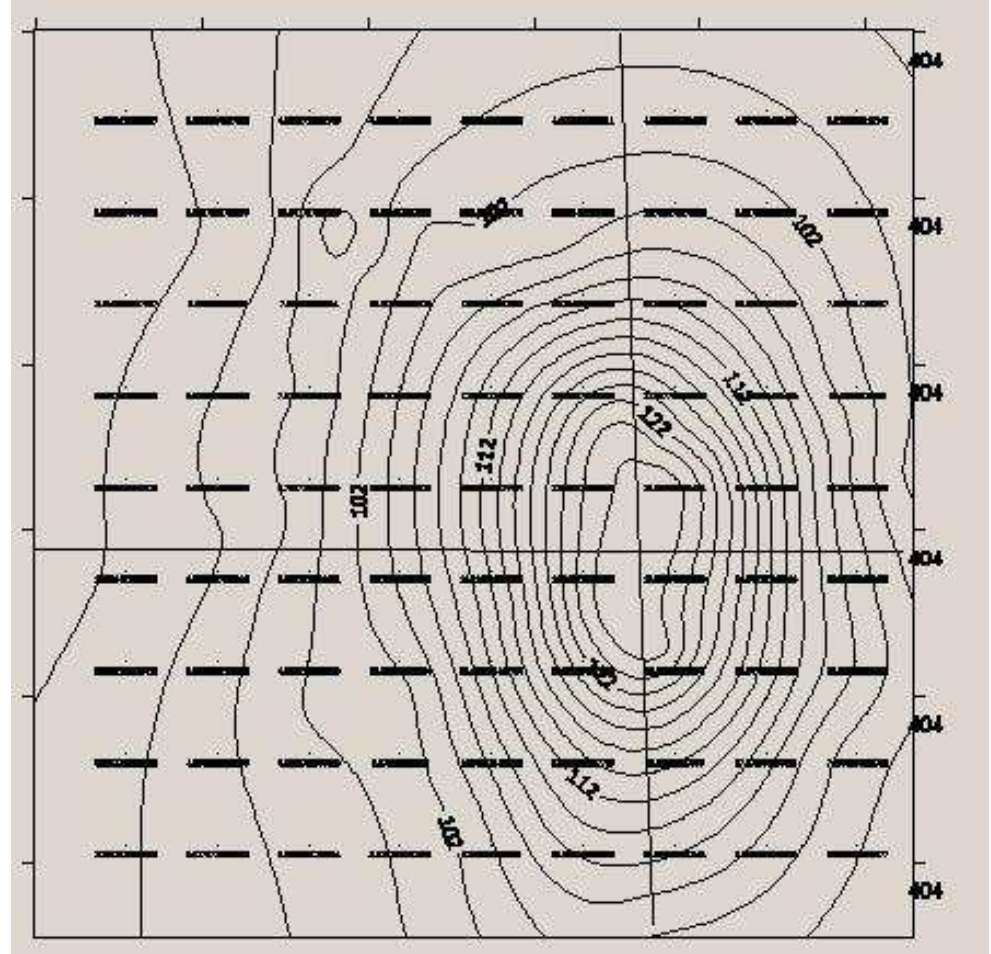

Figure 4:Contour map and a network of inclination angles of the area. 


\section{CONCLUSIONS}

The way to use total station to get digital levels is better than the old device's methods in terms of speed. The loss of accuracy is very small, especially in natural lands. We have produced an inclination grid the can easily identify critical slopes in the area, for the sake of safety of soil movement and ease of access.

\section{ACKNOWLEDGEMENTS}

Author is grateful to the assistance provided by Mr. GhassanNajim and the University of Mosul to ease carrying this work.

\section{REFERENCES}

1- Wolf, P. R (2002), “Surveying and mapping: History, current status and future projections.” J. Surv. Eng., 128,3, 79-106.

2- Kavanagh F. Barry, (2010), "Surveying With Construction Applications", $7^{\text {th }}$ Ed. Prentice Hall.

3- Charles D. Ghilani, P. Wolf, (2008), "Elementary Surveying An Introduction to Geomatics", $12^{\text {th }}$ ed. Printice Hall.

4- Topcon Corporation, (2009), "Topcon GTS-235 Total Station Guide”

5- Ghilani, Charles D., Paul R. Wolf.(2006), "Adjustment computations : spatial data analysis" $4^{\text {th }}$ ed. John Wiley \& Sons. 

